\title{
Transcriptomic analysis of candidate osmoregulatory genes in the eastern oyster Crassostrea virginica
}

\author{
Laura E Eierman ${ }^{*}$ and Matthew P Hare
}

\begin{abstract}
Background: The eastern oyster, Crassostrea virginica, is a euryhaline species that can thrive across a wide range of salinities (5-35). As with all estuarine species, individual oysters must be able to regulate their osmotic balance in response to constant temporal variation in salinity. At the population level, recurrent viability selection may be an additional mechanism shaping adaptive osmoregulatory phenotypes at the margins of oyster salinity tolerance. To identify candidate genes for osmoregulation, we sequenced, assembled, and annotated the transcriptome of wild juvenile eastern oysters from 'high' and 'low' salinity regimes. Annotations and candidates were mostly based on the Pacific oyster (Crassostrea gigas) genome sequence so osmoregulatory relevance in C. virginica was explored by testing functional enrichment of genes showing spatially discrete patterns of expression and by quantifying coding sequence divergence.

Results: The assembly of sequence reads and permissive clustering of potentially oversplit alleles resulted in 98,729 reftigs (contigs and singletons). Of these, 50,736 were annotated with 9,307 belonging to a set of candidate osmoregulatory genes identified from the C. gigas genome. A total of 218,777 SNPs (0.0185 SNPs/bp) were identified in annotated reftigs of $C$. virginica. Amino acid divergence between translations of $C$. virginica annotated reftigs and $C$. gigas coding sequence averaged $23.2 \%$ with an average $\mathrm{dN} / \mathrm{dS}$ ratio of 0.074 , suggesting purifying selection on protein sequences. The high and low salinity source oysters each expressed a subset of genes unique to that group, and the functions for these annotated genes were consistent with known molecular mechanisms for osmotic regulation in molluscs.

Conclusions: Most of the osmoregulatory gene candidates experimentally identified in C. gigas are present in this C. virginica transcriptome. In general these congeners show coding sequence divergence too high to make the $C$. gigas genome a useful reference for $C$. virginica bioinformatics. However, strong purifying selection is characteristic of the osmoregulatory candidates so functional annotations are likely to correspond. An initial examination of C. virginica presence/absence expression patterns across the salinity gradient in a single estuary suggests that many of these candidates have expression patterns that co-vary with salinity, consistent with osmoregulatory function in C. virginica.
\end{abstract}

Keywords: Crassostrea virginica, Osmoregulation, Transcriptome, dN/dS, Gene enrichment, SNP, Cd-hit

\section{Background}

The eastern oyster (Crassostrea virginica) builds reefs that support productive estuarine communities and provide important ecosystem services [1,2]. However, overfishing, disease pressure, and environmental stress have led to the loss of approximately $90 \%$ of biomass across the eastern oyster's home range since the early 1900's [3-5]. Two important topics in oyster biology and restoration are

\footnotetext{
*Correspondence: lee27@cornell.edu
Department of Natural Resources, Cornell University, 213 Bradfield Hall,
Ithaca, NY 14853, USA

* Correspondence: lee27@cornell.edu
Department of Natural Resources, Cornell University, 213 Bradfield Hall,
Ithaca, NY 14853, USA *Correspondence: lee27@cornell.edu
Department of Natural Resources, Cornell University, 213 Bradfield Hall,
Ithaca, NY 14853, USA
}

(c) 2014 Eierman and Hare; licensee BioMed Central Ltd. This is an Open Access article distributed under the terms of the Creative Commons Attribution License (http://creativecommons.org/licenses/by/2.0), which permits unrestricted use, distribution, and reproduction in any medium, provided the original work is properly credited. The Creative Commons Public Domain Dedication waiver (http://creativecommons.org/publicdomain/zero/1.0/) applies to the data made available in this article, unless otherwise stated.

the mechanisms by which oysters respond to stress [6,7] and the ability of oyster populations to either acclimate to stress through phenotypic plasticity or adapt via selection. The majority of work on eastern oysters has focused on immune response to pathogens [8-11] with a few observational studies on other environmental stressors $[6,12]$. Spatial and temporal variation in salinity is a given for estuaries, and phenotypic buffering of cell volume through osmolyte control is an essential adaptation for all organisms that live there.

Eastern oysters are found along salinity gradients ranging from near freshwater conditions (salinity of 5) to oceanic 
salinities (salinity of 35) [13-15]. Their greatest abundance is typically at intermediate salinities, with the adult physiological optimum posited to be as narrow as salinities of 15-18 [15]. At the margins of this environmental envelope, recent results suggest that post-settlement viability selection is one important process for sustaining adult populations [16]. While the genes involved in osmoregulation have not been well characterized in the eastern oyster, recent studies on the Pacific oyster (Crassostrea gigas) [17-19] provide valuable tools for investigating the genetics of osmoregulation. Generating genome-scale resources such as transcriptome sequences for $C$. virginica can facilitate studies of gene expression and the physiology of osmoregulation in order to better understand responses to osmotic stress at the individual and population levels.

Oysters regulate cell volume in response to changing salinity through multiple mechanisms. Oysters are osmoconformers with no ability to osmoregulate their extracellular fluid [20]. Salinity fluctuations therefore result in energetically costly processes to maintain isoosmostic balance by accumulating or releasing osmotically active solutes (osmolytes) [20]. These osmolytes include both inorganic ions such as $\mathrm{N}^{+}, \mathrm{K}^{+}$and $\mathrm{Ca}^{2+}$ and organic substances such as free amino acids (FAA) and quaternary amines [21]. Oysters, like many organisms when under great osmotic stress, primarily use organic osmolytes such as taurine, alanine, aspartic acid, glycine, and betaine [21-23]. Organic osmolytes are able to provide osmotic bulk under high osmotic stress without the direct physiological trade-offs that inorganic ions would have [24]. Furthermore, organic osmolytes can stabilize proteins and protect cells from oxidative stress [20,24]. A variety of functional classes of enzymes are likely involved in osmoregulation, including peptidases to catalyze the hydrolysis of peptides into amino acids, kinases to phosphorylate plasma membrane proteins, and transporters to move molecules across cell membranes [20].

Most molecular physiological studies of osmoregulation in oysters have focused on the products of single genes, such as taurine transporter $[25,26]$. The $C$. gigas genome sequence and the initial evaluation of gene expression between salinity treatments [17] demonstrated differential expression for hundreds of genes. Genomic studies of $C$. virginica gene expression across natural salinity gradients have also shown many genes responding to this environmental gradient [6]. To enable more focused future studies on osmoregulation in C. virginica, a first step is the identification of candidate genes involved in this core physiological process.

Our objective was to identify genes putatively involved in osmoregulation in the eastern oyster by sequencing, assembling, and annotating the transcriptome from lowand high-salinity source populations of juvenile oysters by using 454 sequencing technology. Using annotations and differential expression data from C. gigas, we identified C. virginica transcripts that are candidates for osmoregulatory function. Given that these congeners shared a common ancestor more than 82 Mya [27], we explored the functional appropriateness of these annotations in two ways. First, we quantified the distribution of coding sequence divergence and estimated the strength of purifying selection maintaining similar polypeptide sequences in the two species. Second, we tested for predicted expression patterns in normalized cDNA libraries from low- and high-salinity wild oysters. Specifically, we predicted that transcripts found in one salinity population but not the other would be enriched for candidate osmoregulatory genes and for osmoregulation-related gene ontology terms (GO; www.geneontology.org). Our evaluation of this transcriptome and results of these associated analyses provide some confidence that these candidate genes are a comprehensive starting point for experiments investigating the physiological and evolutionary responses of eastern oysters to osmoregulatory challenges in their estuarine environment.

\section{Methods}

\section{Sample collection and archiving}

Shell substrate was deployed at a "high" salinity field site $\left(27^{\circ} 10^{\prime} 58.2^{\prime \prime} \mathrm{N} 80^{\circ} 12^{\prime} 22.2^{\prime \prime} \mathrm{W}\right.$; mean salinity = 15.9, $\max =$ $33.5, \min =4.6)$ and at a "low" salinity field site $\left(27^{\circ}\right.$ $13^{\prime} 11.2^{\prime \prime} \mathrm{N} 80^{\circ} 13^{\prime} 38.9^{\prime \prime} \mathrm{W}$; mean salinity $=8.0, \max =18.2$, $\min =1.0)$ in the St. Lucie River, Florida, on June 2, 2010. Water temperature, salinity, and percent dissolved oxygen were recorded every hour at both sites from March 23, 2010 until July 1, 2010 with a Sonde (YSI 600OMS V2). Over this time interval these two sites were significantly different in salinity (Figure $1, \mathrm{t}=-38.6, \mathrm{df}=1397, \mathrm{p}<0.001$ ). Mean water temperature was $26.5^{\circ} \mathrm{C}$ at the high salinity site and $27.4^{\circ} \mathrm{C}$ at the low salinity site. Mean dissolved oxygen was $83.1 \%$ at the high salinity site and $86.6 \%$ at the low salinity site. The temperature and dissolved oxygen did not differ significantly between the sites $(\mathrm{p}=0.062, \mathrm{p}=0.091)$. Juvenile oysters (spat; $4-10 \mathrm{~mm}$ total length) were collected from the shell substrate on July 1, 2010. All soft tissue, including gill, mantle and adductor muscle, was archived for each individual in RNALater ${ }^{\circledR}$ (Ambion) after removing the visible digestive system. Within two weeks, the RNALater ${ }^{\circledR}$ was drained and the samples were archived at $-80^{\circ} \mathrm{C}$.

\section{RNA extraction}

Approximately $30 \mathrm{mg}$ tissue from each of four individuals per site was used for individual RNA extractions using Qiagen RNeasy Mini Kit (Qiagen, Valencia, CA) following the manufacturer's protocol. Total RNA from each sample was quantified using NanoDrop 8000 (ThermoScientific) and $5 \mu \mathrm{g}$ from each of four individuals per site was pooled. 


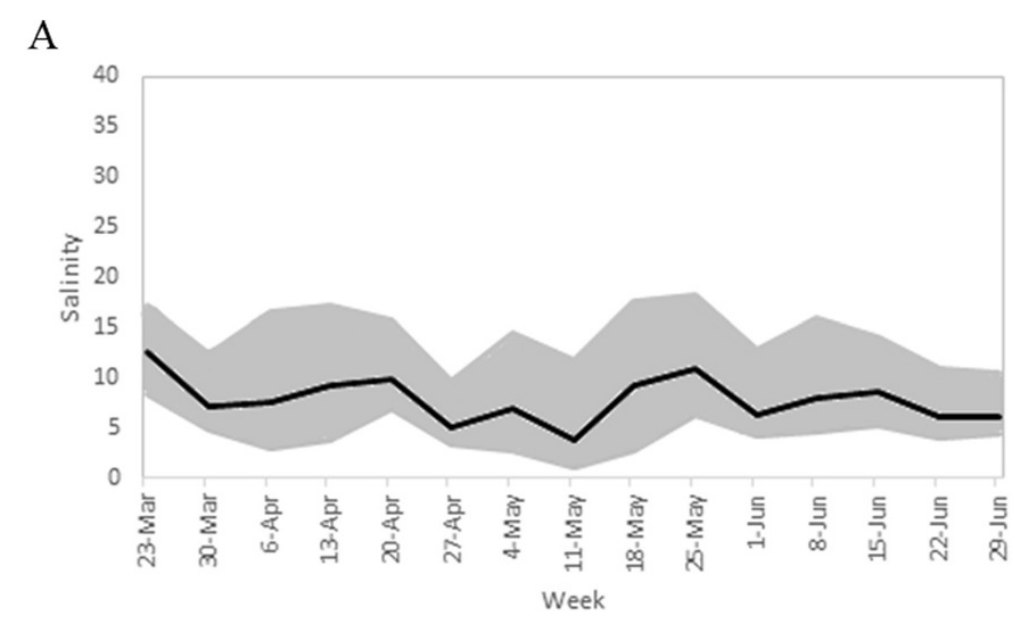

B

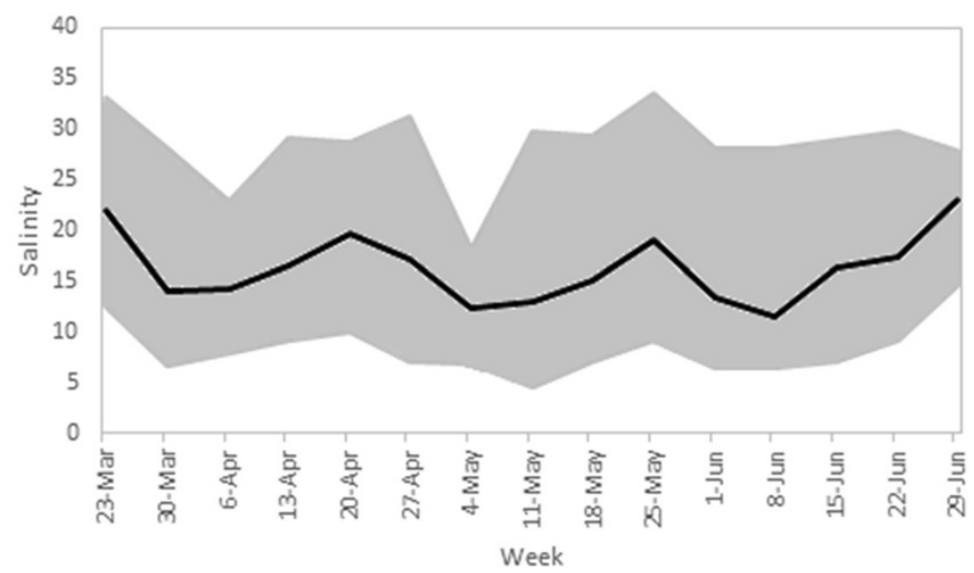

Figure 1 Salinity at the 'high' and 'low' wild juvenile oyster collections sites. A) Maximum, mean, and minimum salinity at low salinity site. B) Maximum, mean, and minimum salinity at high salinity site.

\section{4 library prep and sequencing}

The construction of two normalized cDNA libraries and 454 pyrosequencing was carried out at the W.M. Keck Center for Comparative and Functional Genomics, Roy J. Carver Biotechnology Center, University of Illinois at Urbana-Champaign. We chose to normalize the libraries in order to increase the likelihood that rare transcripts would be sequenced, leading to a more complete transcriptome with limited sequencing effort. For each library, messenger RNA was isolated from $10 \mu \mathrm{g}$ of pooled total RNA with the Oligotex kit (Qiagen, Valencia, CA). The messenger RNA was then converted to a primary cDNA library with adaptors compatible with the 454 system using Multiplex Identifier (MID) tags to distinguish the two population pools [28]. The libraries were diluted to $1 \times 10^{6}$ molecules $/ \mu \mathrm{L}$, pooled, and sequenced on a full plate using the 454 Genome Sequencer FLX + system according to the manufacturer's instructions (454 Life Sciences, Branford, CT). Signal processing and base calling were performed using the bundled 454 Data Analysis Software v2.6.

\section{Transcriptome assembly and clustering}

The two barcoded sets of reads were independently trimmed prior to assembly. Reads were trimmed from each end using a phred-scale quality score of 20 with fastq_quality_trimmer (FASTXToolkit). When the trimmer encountered a base pair with a quality less than 20, the closest read end was trimmed up to that base. Reads with less than $70 \%$ of the original length remaining were discarded. Trimmed reads were then imported into Newbler (gsAssembler, 454 Life Sciences, Roche Diagnostics). Any remaining adapters were trimmed, and reads were filtered against an $E$. coli database to remove contaminants. Reads were then assembled de novo using the default settings except for a minimum overlap length of $30 \mathrm{bp}$ (default $40 \mathrm{bp}$ ). The quality of the initial assembly was evaluated by comparing assembly statistics to other published molluscan transcriptomes from 454 sequencing. Newbler reports consensus "contigs" using the overlap-layout-census (OLC) approach, which merges reads into contigs when their alignments overlap. Reads with no alignment overlap with other reads are denoted as singletons. Because singletons 
may belong to unique genes that were not highly expressed, they were included in further analysis. We defined a reference transcriptome as the combined set of $200 \mathrm{bp}$ or longer contigs (consensus from multiple overlapping reads) and singletons and hereafter refer to these as "reftigs" (reference transcriptome sequences).

Large indels, highly polymorphic sequences, and other de novo assembly challenges can often lead to redundancy in sequences between singletons and contigs [29]. Particularly in highly polymorphic species such as oysters, alleles will often assemble into separate contigs or remain as singletons. This redundancy complicates downstream applications of the resulting transcriptome, such as gene expression analyses [30], because reads from some single copy genes will not map uniquely within the transcriptome and may be discarded. We assumed that the reftigs from the Newbler assembly included many oversplit loci, so to improve the transcriptome we consolidated redundant reftigs by clustering. Cd-hit [31] was used to cluster reftigs with various sequence identity thresholds ranging from permissive clustering at $80 \%$ to conservative clustering at $99 \%$ using a $\mathrm{k}$-mer word size of 5 to 10 increasing incrementally with the threshold (e.g. word size 5 with threshold 80\%).

Several approaches were used to evaluate whether clustering improved the transcriptome. For the $80 \%$ and 95\% clustering results we compared statistics bearing on transcriptome quality including the percent of reftigs that were annotated, the distribution of annotation between contigs and singletons, and the number of osmoregulatory candidates (identified in C. gigas) recovered.

Additionally, we evaluated the two clustering results by comparing the proportion of Illumina reads from a barcoded individual that uniquely mapped to annotated reftigs based on a pilot RNA-seq experiment. The barcoded individual was from an oyster reef in Delaware Bay with a salinity regime ranging from 6.5 to 14.5 . The mRNA from $30 \mathrm{mg}$ of gill tissue was extracted using Dynabeads ${ }^{\bullet}$ mRNA DIRECT $^{\mathrm{TM}}$ kit (Life Technologies). The library was prepared with NEBNext ${ }^{\oplus}$ mRNA Library Pep Reagent Set for Illumina (New England BioLabs Inc.). The library constituted $16.25 \%$ of a single $100 \mathrm{bp} \mathrm{Hi-Seq} \mathrm{Illumina} \mathrm{lane} \mathrm{and} \mathrm{was}$ sequenced at the Biotechnology Resource Center Genomics Facility of Cornell University. The resulting reads were trimmed following the same procedure as the 454 reads, and any remaining adapters were clipped using fastx_clipper (FASTXToolkit). The remaining reads were then mapped to the annotated reftigs using BWA [32] with a mismatch edit distance of 0.005 and SAMtools [33] with only uniquely mapped reads retained.

\section{Annotation}

To annotate the de novo $C$. virginica transcriptome assembly, reftigs were compared to NCBI's non-redundant (nr) protein sequence database that included the annotated proteins deduced from the C. gigas genome (May 2013), plus the Swiss-Prot and TrEMBL databases from the Uniprot protein knowledge base, using the BLASTx algorithm with an e-value cut-off of $10^{-5}$. Gene Ontology (GO; www.geneontology.org) annotation was retrieved from Uniprot. The annotated and unannotated reftigs were then compared with respect to the proportion of contigs and singletons as well as GC content in order to explore if unannotated reftigs may represent non-oyster contamination in the 454 sequences. The number of unique genes represented by the transcriptome was then identified by grouping reftigs that shared the same GenBank gene identifier.

We considered genes as osmoregulatory candidates if they were included in the 1,241 annotated genes found to be differentially expressed in $C$. gigas adults in response to six different salinity treatments when compared to a control salinity of 30 Table S21 in [17]. Additionally, we quantified the number of genes in the normalized libraries that were uniquely represented in one $C$. virginica population sample or the other by mapping the trimmed and filtered 454 read pools from 'low' and 'high' salinity samples back to the annotated reftigs from the $80 \%$-clustered transcriptome using GSMapper (454 Life Sciences, Roche Diagnostics) with default settings. Enrichment of functional classes was tested at the level of genes, based on reftig annotation results described below, for two subsets compared to the entire annotated transcriptome: (1) all osmoregulatory candidates and (2) genes unique to each population. Enrichment tests used a Fisher's exact test as implemented in TopGO from Bioconductor [34]. Genes that were unique to one of the two populations were identified as "asymmetric." Results from enrichment tests were depicted in the context of the hierarchical structure of gene ontology terms in order to visualize the degree of functional integration among the most significantly enriched genes.

\section{Sequence comparisons with C. gigas}

Simple sequence repeats and low complexity regions of the annotated reftigs were masked with RepeatMasker [35], using the rmblast search engine. Reftigs with masked regions were removed from analysis. The coding sequence reading frame for each remaining reftig was then predicted using ESTscan [36]. ESTscan was trained using the EMBL, RefSeq and UniGene clusters from the mollusk Aplysia californica, the most closely related species for which a full set of references were available at the time of this study. The matrices from this training were then used to predict coding sequences for the reftigs using a hidden Markov model [36]. The predicted coding sequence for each reftig was then used to analyze sequence divergence from $C$. gigas.

A local directory of $C$. gigas coding sequence for predicted proteins from the C. gigas genome was downloaded 
from http://gigadb.org/dataset/view/id/100030/sort/size and clustered with $\mathrm{Cd}$-hit using the same parameters as for reftig clustering (sequence identity threshold $=0.8$, word size $=5$ ). Coding sequences that clustered were assumed to be paralogs and removed from analysis to reduce the bias that would occur with comparison of paralogs between C. gigas and C. virginica. The C. virginica reftigs were then compared against the $C$. gigas coding sequences using tBLASTx with intron linking disabled and an e-value cutoff of $10^{-5}$. Best hits were interpreted as putative ortholog pairs for analysis. Ortholog pairs were then run through a custom pipeline to align sequences using ClustalW [37] and calculate $\mathrm{dN} / \mathrm{dS}$ ratios using the codeml function of paml [38]. The distribution of $\mathrm{dN} / \mathrm{dS}$ values relative to ClustalW alignment length was evaluated before choosing to remove alignments less than $60 \%$ of the total reftig length.

\section{SNP discovery}

The mapped 454 reads from both population samples were combined and aligned against the masked, annotated reftigs with mpileup of SAMtools [33]. SNPs were then identified using SNAPE-pooled [39] with a base quality average of 37 or greater, theta of 0.01 , divergence of 0.1 , flat prior and folded spectrum, and the SNP density for each contig was calculated.

\section{Results and discussion}

\section{Assembly and clustering results}

A total of 1,256,652 raw 454 reads included 718,009 from the high salinity population and 538,553 from the low salinity population. The raw reads are available through the National Center for Biotechnology Information Short Read Archive under accession numbers SRS502377 for the high salinity population and SRS502378 for the low salinity population. After trimming and filtering, 1,182,107 reads remained and were assembled into 28,939 contigs that contained $86.7 \%$ of the reads. The 128,083 unassembled reads were designated as singletons and included in further analysis. The combined contig and singleton set consisted of 157,022 reftigs. The assembly size for contigs alone was approximately 18,202,631 nucleotide bases, similar to other molluscan transcriptome assemblies based on 454 sequences (Table 1), and had an average contig length of 629.1 bases (N50 $=500$ bases) and maximum contig length of 7,512 bases. The total transcriptome (contigs and singletons, 157,022 reftigs) was 51,918,466 nucleotides with an average length of 453.0 bases (N50 = 381 bases).

Given the high degree of polymorphism in oysters [17], clustering of assembled reftigs was explored as a method of consolidating alleles that remained apart after assembly. Consolidating alleles is an important consideration before using a transcriptome assembly as a reference for RNAseq expression analyses because oversplit alleles in the assembly will decrease the number of reads that map uniquely. A total of 136,000 reftigs (86.7\%) were longer than $200 \mathrm{bp}$ and used for clustering at different sequence identity thresholds. Comparing the change in total reftig number resulting from increasingly permissive clustering, the rate of reftig consolidation was initially rapid based on thresholds from $99 \%$ to $95 \%$; then the rate of change slowed and was nearly constant between $95 \%$ and $80 \%$ (Figure 2). As the sequence identity threshold decreased, the ratio of contigs to singletons increased as expected if singletons were being clustered with greater frequency than contigs (Table 2).

Transcriptomes resulting from both the 95\% and $80 \%$ sequence identity thresholds were annotated for comparison. Both transcriptomes had a similar percentage of reftigs successfully annotated, with a similar distribution of contigs and singletons. Likewise, 1,014 osmoregulatory candidates (see below) were obtained with the 95\% threshold and this dropped by only seven candidate genes at the $80 \%$ threshold (Table 2). The large percentage (99.4\%) of candidate genes that remain in the transcriptome at the $80 \%$ threshold compared to the 95\% threshold suggests that any potential paralog clustering resulted in a minimal loss in the number of uniquely annotated genes, particularly osmoregulatory candidates.

We mapped 100 bp Illumina RNAseq reads from a single individual to the $95 \%$ and $80 \%$ transcriptomes to test whether oversplit alleles were consolidated by clustering. Relative to the $95 \%$ transcriptome, the $80 \%$ transcriptome had a higher percentage of annotated reftigs with mapped reads, but the effect was small (Table 2). In terms of the proportion of Illumina reads that mapped, two percent more reads mapped uniquely to the $80 \%$ transcriptome than the $95 \%$ transcriptome. The increase in the percent of uniquely mapped reads in the $80 \%$ transcriptome suggests that consolidation of allelic reftigs was achieved by clustering, resulting in more reads mapping uniquely. Based on these results the $80 \%$ threshold transcriptome was chosen for further analysis.

In one cluster examined in more detail, an original contig annotated as Heat Shock 70 kDA Protein 12 was ultimately clustered with three singletons. Two singletons clustered at the $95 \%$ threshold. The third singleton (330 bp) was unannotated at the 95\% threshold. With a similarity of $84.55 \%$ estimated by Cd-hit, it was clustered with the contig and the other two singletons at the $80 \%$ threshold. An alignment between this third singleton and the original contig showed five indels ranging in size from 1 to $17 \mathrm{bp}$ and two polymorphisms as the cause for the $84.55 \%$ sequence identity. We suspect these indels represent 454 sequencing error because they were partially shared across the three singletons, most of them would disrupt the reading frame, and they occurred within simple nucleotide repeats and low complexity sequence. Some 
Table 1 Assembly comparison to other molluscan transcriptomes sequenced using 454 technology

\begin{tabular}{|c|c|c|c|c|c|c|c|c|c|}
\hline Species & Normalized & $\begin{array}{l}\text { Mean unfiltered } \\
\text { read length (bp) }\end{array}$ & Unfiltered reads $(\mathrm{n})$ & Assembler & $\begin{array}{l}\% \text { of filtered } \\
\text { reads assembled }\end{array}$ & Contigs (n) & $\begin{array}{l}\text { Mean contig } \\
\text { length }(b p)\end{array}$ & $\begin{array}{l}\text { Estimated total } \\
\text { assembly (bp) }\end{array}$ & Reference \\
\hline Mytilus edulis & No & 279 & $2,393,441$ & Celera, Cap3 & 92.0 & 74,622 & 645 & $48,131,190$ & [40] \\
\hline Bathymodiolus azoricus & Yes & 283 & 778,996 & MIRA & 74.8 & 75,407 & 509 & $38,382,163$ & [41] \\
\hline Hyriopsis cumingii & No & 296 & 981,302 & Cap3 & 70.5 & 47,812 & 634 & $30,312,808$ & [42] \\
\hline Meretrix meretrix & No & 413 & 751,970 & Cap3 & 87.3 & 35,205 & 679 & $23,904,195$ & [43] \\
\hline Patinopecten yessoensis & Yes/No & 313 & 970,422 & Cap3 & 86.7 & 32,590 & 618 & $20,140,620$ & [44] \\
\hline Crassostrea virginica & Yes & 343 & $1,256,652$ & Newbler & 86.8 & 28,939 & 629 & $18,202,631$ & Present study \\
\hline Ruditapes philippinarum & Yes & - & 457,717 & MIRA3 & - & 32,606 & 546 & $17,802,876$ & [45] \\
\hline Chamelea gallina & Yes & 210 & 298,494 & MIRA & - & 39,750 & 352 & $13,992,000$ & {$[46]$} \\
\hline Laternula elliptica & No & 369 & $1,034,155$ & Newbler & 33.9 & 18,290 & 535 & $9,785,150$ & {$[47]$} \\
\hline Crassostrea angulata & No & 309 & 555,215 & Newbler & 79.9 & 10,462 & 723 & $1,057,026$ & [48] \\
\hline Pinctada martensii & No & 349 & 434,650 & Newbler & - & 3,574 & - & - & [49] \\
\hline Pinctada margaritifera & No & 234 & 276,738 & $\mathrm{TGICL}$ & 79.2 & 76,790 & - & - & [50] \\
\hline
\end{tabular}

The assemblies are ordered in decreasing size of estimated total assembly. ${ }^{*}$ This calculation is from the mean contig length and number of assembled contigs and is provided as a means to compare transcriptome size. 


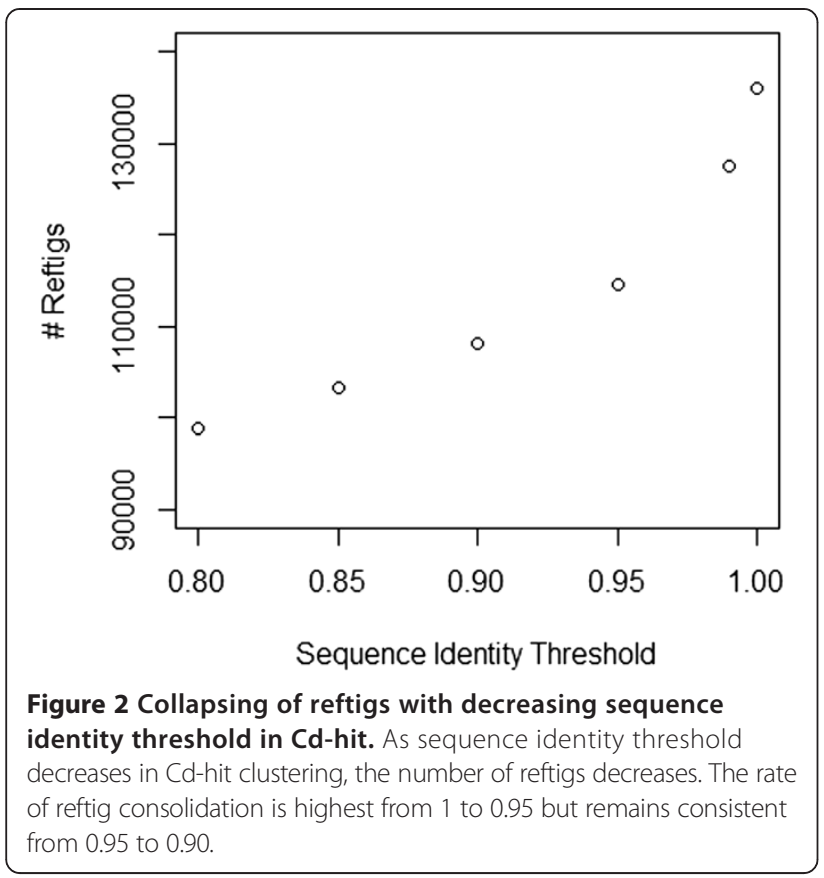

of the SNPs present in the singletons may also be sequencing error but not obviously so; most were not adjacent to indels and they were already represented in the original contig. Therefore, clustering provided two distinct transcriptome improvements: (1) oversplit alleles were consolidated, facilitating downstream mapping to the transcriptome for RNAseq expression analysis, and (2) more of the 454 sequencing coverage was used to call SNPs.
The optimum balance between consolidating oversplit alleles and clustering paralogs or sequence errors is impossible to know because it depends on the distribution of allelic sequence differences relative to paralog differences in any particular species as well as the sequencing error rate. The comparative approach used here was ad hoc and took advantage of computational efficiencies when clustering consensus sequences from an assembly rather than exploring parameter values in separate assemblies. When no reference genome is available, this comparative empirical approach can be a valuable method of improving transcriptome quality.

\section{Annotation results}

The BLASTx search against multiple databases provided annotation for 50,736 reftigs (51.4\%) representing 20,249 unique GenBank accessions and 16,392 distinct putative proteins that we will refer to as genes. Only $0.05 \%$ of the annotations were achieved with a database other than GenBank nr (Figure 3). Reftigs that did not have a BLASTx match with an e-value smaller than $10^{-5}$ from any database was designated as unannotated.

Of 16,392 distinct genes, 8,161 are represented by a single reftig. The number of reftigs per gene ranges from 1 to 470 with only 13 genes represented by 100 or more reftigs. Gene duplication and large gene families, particularly in the C. gigas genome from which $89 \%$ of our annotations were identified, are the primary reasons for the large number of reftigs per "gene". For example, the 456 reftigs identified as the gene "tripartite motif-containing protein 2" from C. gigas were annotated from 201 unique

Table 2 Comparison of quality statistics for transcriptome assembly at unclustered, $95 \%$ and $80 \%$ sequence identity thresholds

\begin{tabular}{|c|c|c|c|}
\hline & Unclustered & $95 \%$ sequence identity threshold & $80 \%$ sequence identity threshold \\
\hline \multicolumn{4}{|l|}{ Composition } \\
\hline Total \# Reftigs & 136,000 & 114,716 & 98,729 \\
\hline$\%$ Contigs & $16.4 \%$ & $18.9 \%$ & $20.5 \%$ \\
\hline$\%$ Singletons & $83.6 \%$ & $81.1 \%$ & $79.5 \%$ \\
\hline \multicolumn{4}{|l|}{ Annotation } \\
\hline Total reftigs annotated & & 58,811 & 50,736 \\
\hline$\%$ Reftigs annotated & & $51.3 \%$ & $51.4 \%$ \\
\hline$\%$ of Contigs & & $62.6 \%$ & $64.3 \%$ \\
\hline$\%$ of Singletons & & $48.6 \%$ & $48.1 \%$ \\
\hline \# of Osmoregulation candidates & & 1014 & 1007 \\
\hline \multicolumn{4}{|l|}{$\begin{array}{l}\text { Sample illumina reads mapped to } \\
\text { annotated transcriptome }\end{array}$} \\
\hline$\%$ Reftigs with mapped reads & & $86.7 \%$ & $88.3 \%$ \\
\hline$\%$ of Reads mapped uniquely & & $40.8 \%$ & $42.8 \%$ \\
\hline
\end{tabular}

With more permissive clustering, the number of unique sequences in the transcriptome (reftigs) decreases and the proportion of non-singleton reftigs (contigs) increases. The clustering threshold has a trivial effect on the proportion of reftigs annotated and the number of osmoregulatory candidates recovered. With $42.8 \%$ of Illumina reads uniquely mapping, transcriptomes based on more permissive clustering have a greater percentage of annotated reftigs with reads mapped to them as well as a greater percentage of uniquely mapped reads. 


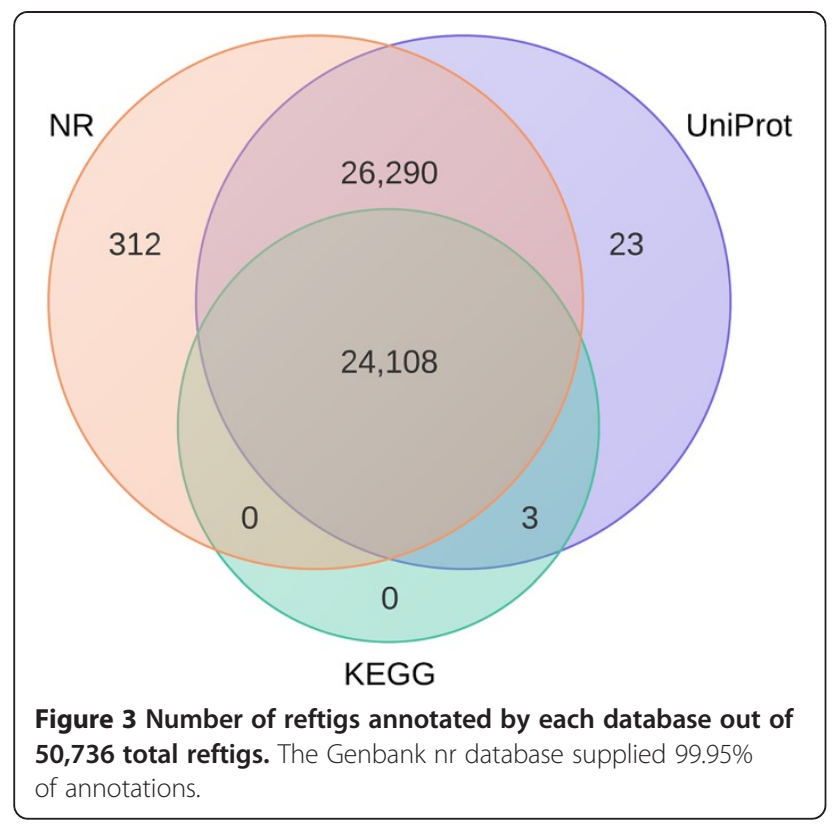

GenBank accessions. For C. gigas, these different GenBank accessions represent different coding sequence locations within the genome. Therefore, we define a "gene" here as a protein product, which often represents large gene families.

Gene Ontology (GO) terms were assigned to 36,924 of the annotated reftigs, representing 11,583 putative genes, based on sequence similarity to known proteins in the UniProt databases. Annotated reftig sequences have been archived and are accessible through FigShare (http://dx. doi.org/10.6084/m9.figshare.873865) [51].

A consequence of whole animal extractions and normalizing the libraries was the increased potential to sequence non-oyster transcripts, such as bacteria and algae. Singletons made up $\sim 74 \%$ of the reftigs in the full (annotated and unannotated) $80 \%$ transcriptome and less than half of the singletons were successfully annotated. Other studies using 454 sequencing also have described singletons as comprising a large proportion of their transcriptome (e.g. 81.7\% [52]; 58.5\% [29]; 55.3\% [53]) with a subset getting annotated. Singletons are the inevitable consequence of assembling transcripts with low coverage, so they are not necessarily indicative of contamination. However, here the mean GC content for annotated reftigs was $44 \%(\mathrm{SD}=5.4 \%)$, very similar to the $45.2 \%(\mathrm{SD}=4.3 \%)$ average for $C$. gigas coding sequences (Figure 4). In contrast, the unannotated portion of the $C$. virginica transcriptome had a significantly different mean GC content of 34.5\% (SD = 5.8\%) (Figure 4; $\mathrm{t}=266, \mathrm{df}=$ 973455, $\mathrm{p}<0.001$ ). The difference in $\mathrm{GC}$ content provides very strong evidence that many of the unannotated reftigs (both contigs and singletons) came from other organisms such as prokaryotes or protozoa. Without the benefit of

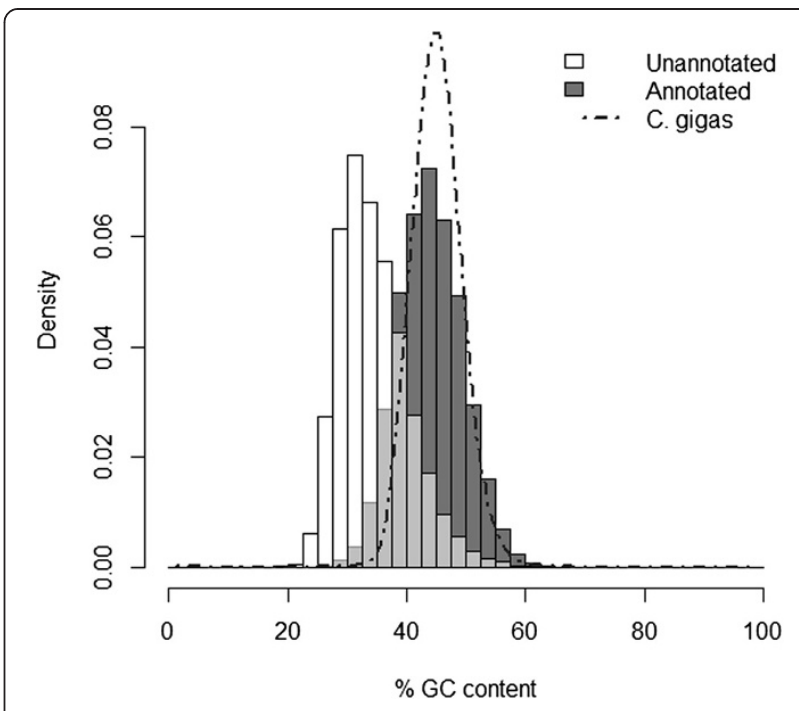

Figure $4 \mathrm{GC}$ content of annotated and unannotated portions of transcriptome and C. gigas. GC content of the annotated portion of the transcriptome is higher than in the unannotated portion, suggesting potential contamination from other species or the presence of other RNA types in the sequencing. The GC content of the annotated portion mirrors the GC content found in the coding sequences of $C$. gigas.

the C. gigas reference genome for annotation and GC content comparison, de novo analysis of the eastern oyster transcriptome generated here would be highly compromised by contaminants.

\section{Osmoregulation candidate genes}

Of the 1,241 osmoregulatory candidate genes identified in C. gigas [17], 1,007 (81.2\%) were identified in the $C$. virginica transcriptome based on 9,307 reftigs $(18.3 \%$ of all annotated reftigs) (Additional file 1: Table S1). The $C$. gigas candidates were identified experimentally based on differentially expressed genes between different salinity treatments of adult oysters [17], while we obtained these transcripts in wild juveniles. Thus, life stage is one factor that could help account for the C. gigas candidates that were not obtained in our samples. Additionally, C. virginica and $C$. gigas have mostly overlapping but slightly different salinity tolerances with $C$. virginica having lower mortality rates than $C$. gigas at low salinity and vice versa at higher salinities [54].

Fifty-nine osmoregulatory candidate genes were identified from only the high salinity population and 56 were identified from only low salinity, together representing $11.4 \%$ of the candidate genes. These asymmetrically expressed candidate genes were mostly cases with $1 x$ coverage (1:0 asymmetry), but 3 genes (2.6\%) had an asymmetry ratio of 5:0 or greater.

Ignoring candidate status, 4,053 of the 16,392 annotated C. virginica genes $(24.7 \%)$ were identified from only one 
of the two populations. Of these, 2,185 were found only in the high-salinity population, including 1,431 genes $(8.7 \%)$ with 1:0 asymmetry and 74 genes $(0.5 \%)$ with $5: 0$ or greater asymmetry. An additional 1,868 genes were found only in the low-salinity population, including 1,355 (8.3\%) with a 1:0 asymmetry and 31 genes $(0.2 \%)$ with $5: 0$ or greater asymmetry. A total of 105 genes (2.6\%) from the two populations had 5:0 or greater asymmetry.

The fact that $24.7 \%$ of all genes showed asymmetry, while only $11 \%$ of osmoregulatory candidates did so, suggests that there may be many biological processes leading to population-specific expression in addition to the stochasticity expected with low-expression genes. Also, given that buffering against osmotic stress is a chronic physiological need for oysters, lower asymmetry among osmoregulatory candidates might reflect the proportion of genes within this functional category that have constitutive expression across salinities.

It is difficult to know how much asymmetry to expect by chance for genes with a given level of expression in normalized libraries. However, enrichment of functional categories within the set of population-specific genes is not expected from stochastic variation in library normalization or read coverage. Our prediction was that among asymmetric genes, annotations related to osmoregulatory function should be the most highly enriched relative to the frequency of functional ontologies in the overall annotated transcriptome. We initially built a frame of reference by testing for functional enrichment among the entire set of osmoregulatory candidate genes in $C$. virginica and found 12 cellular component GO terms and 86 molecular function GO terms significantly enriched compared to the complete annotated gene set (Figures 5 and 6, Additional file 2: Tables S2 and S3). For cellular components, the 'extracellular region', 'plasma membrane' and 'membrane' components were among the significantly enriched terms (Figure 5 and Additional file 2: Table S2). At the level of molecular function, 'catalytic' activities, 'binding' functions, 'electron carrier' activities, 'transporter' activities and 'molecular transducer' activities were among the significantly enriched terms (Figure 6, Additional file 2: Table S3). These enriched GO terms serve to functionally characterize the osmoregulatory candidates on the whole and therefore might be indicators of osmoregulatory function in additional enrichment tests when found in concert.

As predicted, the overall group of asymmetric genes (24.7\% of all genes) showed significantly enriched ontologies relating to osmoregulatory function, as indicated by similarities with enriched GO terms in the total set of osmoregulatory candidate genes. Interestingly, the enriched GO terms were only partially overlapping in the low versus high salinity population, and relative enrichment magnitudes shifted among GO terms. In the low salinity population at the level of cellular components, the strongest result among 12 significantly enriched ontologies included 'integral to membrane' (GO:0016021, $\mathrm{p}=0.00037$ ) and 'intrinsic to membrane' (GO:0031224, p = 0.00058), two ontologies nested within 'membrane' components, the level-three GO term enriched among osmoregulatory candidates (Additional file 2: Table S4). Transmembrane channels are important in maintaining cell volume in response to hypoosmotic stress. For example, $\mathrm{Ca}^{2+}$ channels are upregulated in hypoosmotic stress and osmolytes such as taurine are taken up through high affinity transport systems that may involve transmembrane proteins [18]. Additional terms such as 'cell periphery' (GO:0071944, $\mathrm{p}=0.0033)$, 'plasma membrane part' (GO:0044459, $\mathrm{p}=$ 0.00624 ) and 'plasma membrane' (GO:0005886, $\mathrm{p}=$ $0.00815)$ were terms significantly enriched both in the

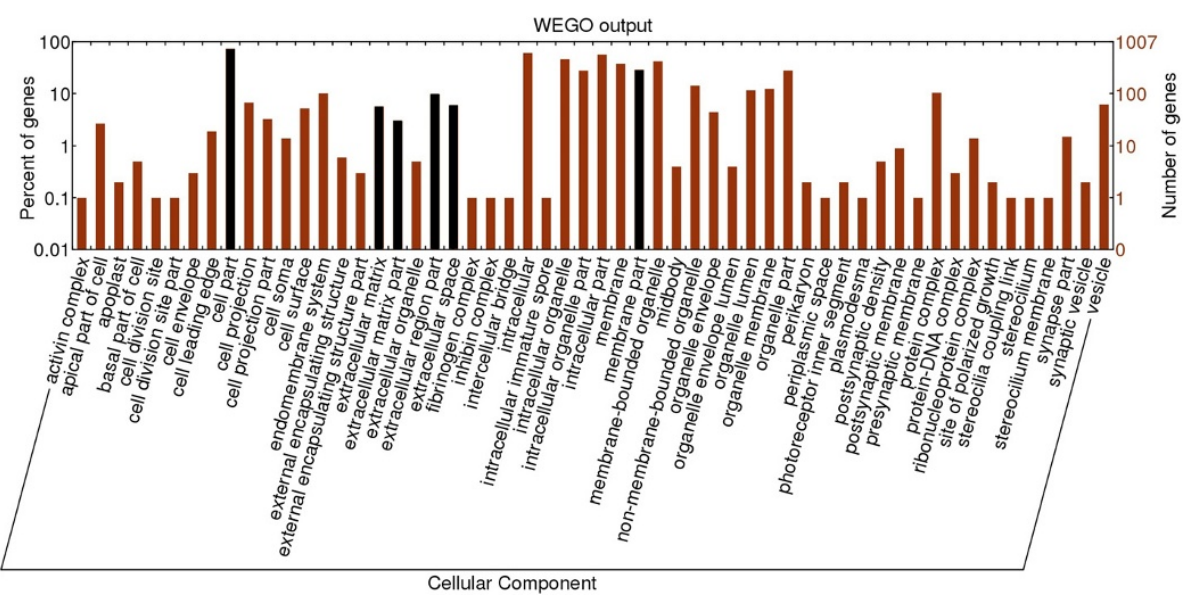

Figure 5 Distribution of level 3 Cellular Component GO terms for the osmoregulatory candidate genes. Black bars indicate the terms or the parents of GO terms that are significantly enriched in the osmoregulatory candidate genes compared to the complete set of annotated genes. 


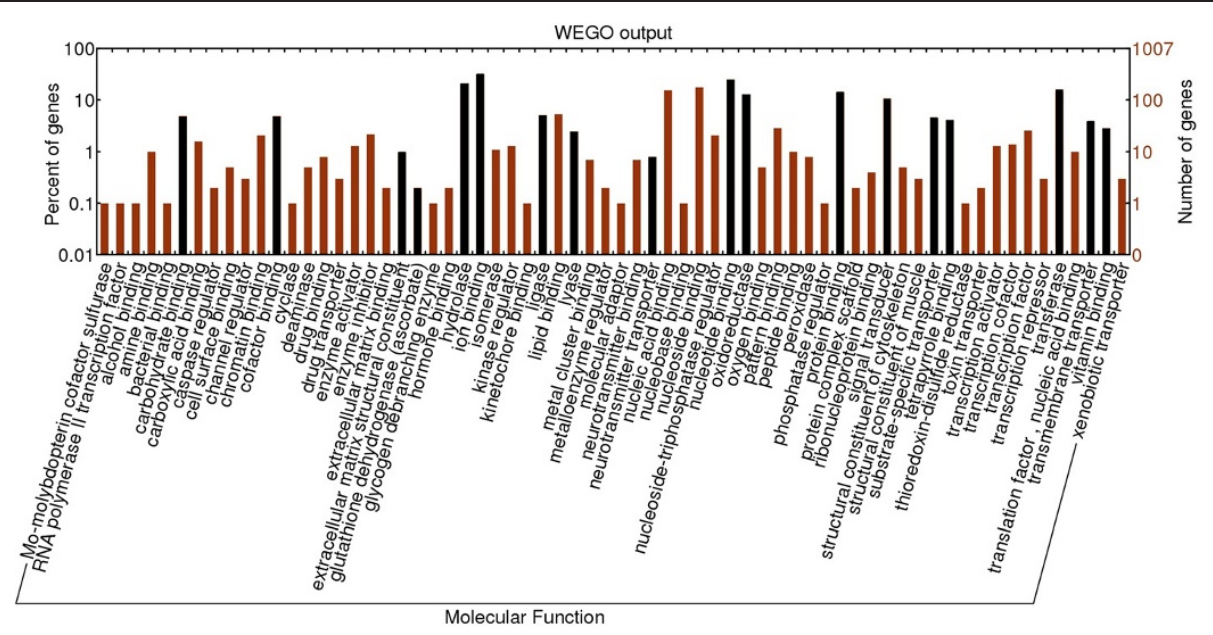

Figure 6 Distribution of level 3 Molecular Function GO terms for the osmoregulatory candidate genes. Black bars indicate the terms or the parents of $\mathrm{GO}$ terms that are significantly enriched in the osmoregulatory candidate genes compared to the complete set of annotated genes.

asymmetric low salinity genes and the full candidate gene set (Additional file 2: Tables S2 and S4). In general, however, the cellular component terms most strongly enriched in the full set of osmoregulatory candidates, extracellular region and its 'children' terms, were not enriched in genes expressed solely at low salinity in $C$. virginica.

In contrast to the low population, the most significant functional enrichment at the level of cellular components in the high population was 'extracellular region' (GO:0005576, $\mathrm{p}=6.4 \mathrm{e}-08$ ). This term refers to the gene products that are secreted from the cell but retained in the interstitial fluid or hemolymph, and it was also the most significantly enriched for the full osmoregulatory candidate gene set (Additional file 2: Table S2, Figure 5). While this parent GO term had the highest level of enrichment among the C. gigas genes experimentally associated with salinity treatments [19] (Additional file 2: Table S2), it is also likely to include immune response genes responding to the larger disease burden found in oysters from high salinity $[19,55]$. Several additional GO terms were significantly enriched both in the asymmetric high salinity genes and in the full candidate gene set including 'intrinsic to membrane' (GO:0031224, $\mathrm{p}=6.4 \mathrm{e}-06)$ and 'plasma membrane' (GO:0005886, $\mathrm{p}=1.3 \mathrm{e}-05$ ) (Additional file 2: Tables S2 and S5).

At the molecular functions GO level, both the high and low salinity populations showed the strongest significant enrichments related to DNA replication and transcription/translation (Additional file 2: Tables S6 and S7). For the low salinity population, many of the other significantly enriched molecular function ontologies (Additional file 2: Table S6) were 'children' terms of those significantly enriched both for osmoregulatory genes and for unique low salinity genes (Additional file 2: Tables S3 and S6,
Figure 6). For example, 'G-protein coupled receptor activity' (GO:0004930, $\mathrm{p}=6.6 \mathrm{e}-07$ ) is a 'child' term of 'receptor activity' and 'aspartic-type peptidase activity' (GO:0004190, $\mathrm{p}=2.2 \mathrm{e}-06$ ) is a 'child' term of 'hydrolase activity.' These enriched functions match predictions that the phosphorylation of plasma membrane proteins and the hydrolysis of peptides are part of the physiological response to osmotic stress. For the high salinity population, significant enrichment was found for potential osmoregulatory terms related to 'substrate-specific transporter' and 'transmembrane transporter' activities such as 'receptor activity' (GO:0004872, $\mathrm{p}=7.8 \mathrm{e}-06$ ), 'gated channel activity' (GO:0022839, $\mathrm{p}=0.00022$ ), and 'ion gated channel activity' (GO:0022839, $\mathrm{p}=0.0022$ ) (Additional file 2: Table S7). These enrichment results are consistent with expectations for differential expression of osmoregulatory genes by juvenile eastern oysters from different salinity regimes. Furthermore, it confirms the functional relevance in $C$. virginica of osmoregulatory candidates identified in $C$. gigas.

At the level of reftigs, rather than genes, among those with annotations linked to osmoregulatory function in C. gigas (9703 reftigs), 57.3\% showed expression in only one of the two populations. This high frequency of asymmetry is in striking contrast to the $11 \%$ asymmetry measured at the gene level among osmoregulatory candidates. One possible explanation for this pattern is that asymmetric reftigs represent differentially expressed splice variants of genes expressed by both populations. This hypothesis will be testable with the benefit of this transcriptome as a reference for RNA-seq analyses.

\section{SNP Discovery and dN/dS ratio with C. gigas}

The transcriptome we present here provides the most comprehensive estimate of polymorphism to date for 
C. virginica. Among 13,108 annotated contigs, there was $12,355,575 \mathrm{bp}$ of aligned sequence within which 218,777 SNPs were identified. Average SNP density was 0.0185 per base pair with a standard deviation of 0.0238 (Figure 7). Ninety percent of contigs had at least one predicted SNP. This SNP density falls within the range previously reported for the eastern oyster. Quilang et al. [56] found a rate of $0.0059 \mathrm{SNPs} / \mathrm{bp}$ from 4,688 EST sequences. In contrast, Zhang and Guo [57] estimated $0.042 \mathrm{SNPs} / \mathrm{bp}$ based on resequencing $6.8 \mathrm{~kb}$ of ESTs. Similarly, a single gene study of serine protease inhibitor reported an overall SNP frequency of 0.044/bp [58]. For comparison, SNP density averaged across all exons in wild-caught C. gigas was 0.0102 per bp [17]. Our finding is therefore consistent with previous estimates of nucleotide heterozygosity in C. virginica and tentatively supports the contention that this species is more polymorphic than C. gigas [57].

Quantifying genomic patterns of divergence between C. virginica and C. gigas can help assess the relevance of discoveries in one species with respect to the other. Also, the ratio of substitution rates at nonsynonymous and synonymous sites can help to identify genes undergoing positive selection. After various filtering steps to remove potential artifacts and paralog gene pairs, 26,102 annotated reftigs from C. virginica were paired with an ortholog from C. gigas. Estimates for the number of nonsynonymous substitutions per nonsynonymous site ranged from near 0 to $0.012 /$ bp per ortholog gene pair (Figure 8A) while the number of synonymous substitutions per synonymous site ranged from 0.0003 to $0.66 / \mathrm{bp}$ (Figure $8 \mathrm{~B}$ ). The mean $\mathrm{dN} / \mathrm{dS}$ ratio of $0.074(\mathrm{SD}=0.066$, Figure $8 \mathrm{C})$ indicates a pervasive role for purifying selection maintaining

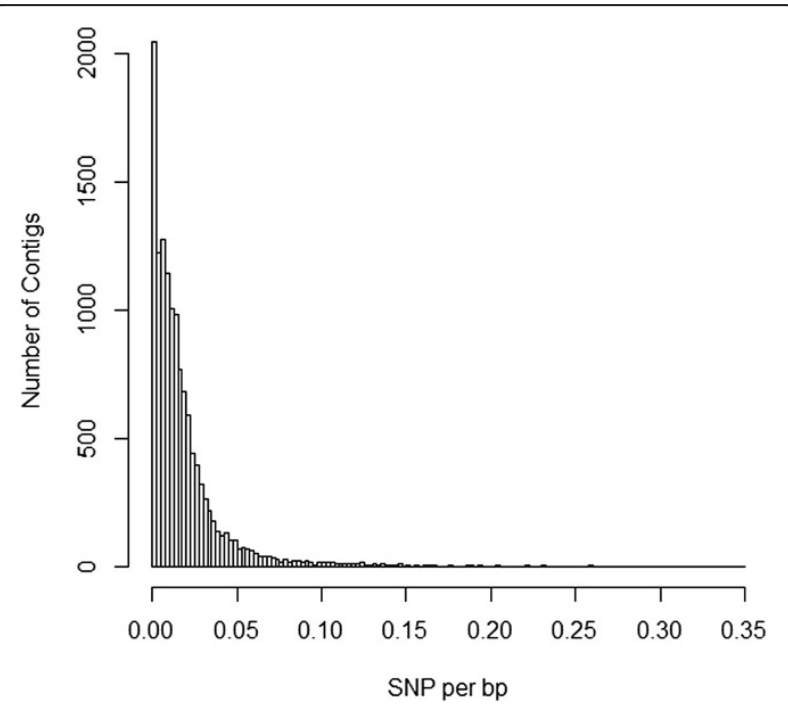

Figure 7 The distribution of SNP density per base pair within annotated contigs from the $80 \%$ clustered transcriptome. similar amino acid sequences. The mean protein similarity was $76.8 \%$, and the mean nucleotide similarity was $74.2 \%$. It is possible that these divergence estimates between the oyster congeners are biased downward because filtering steps (see Methods) inevitably removed some more divergent ortholog pairs.

This degree of purifying selection provides some confidence that functional candidate genes identified in $C$. gigas will often be applicable to $C$. virginica, at least as a starting point. At the same time, transcriptomes in these two species are probably too diverged to expect $C$. gigas genomic reference sequences to help with $C$. virginica bioinformatics. A simulation study by Vijay et al. [59] demonstrated that reference genomes with average nucleotide sequence divergence up to $15 \%$ can help improve transcriptome assemblies while with greater divergence there was no improvement over a de novo assembly. Similarly, the potential for a heterologous reference genome to provide improved RNA-seq analyses, relative to a de novo transcriptome assembly, was determined to be at nucleotide sequence divergences less than $15 \%$ [59].

\section{Conclusions}

The goal of our study was to assemble and annotate the C. virginica transcriptome with particular focus on potential osmoregulatory genes. Largely with the benefit of the Pacific oyster genome, we assigned provisional annotations to 50,736 reftigs representing over 16,000 putative proteins. More than $80 \%$ of the osmoregulatory gene candidates identified in C. gigas experiments with adults were identified here in wild juvenile samples from different salinities. The low $\mathrm{dN} / \mathrm{dS}$ between $C$. virginica and C. gigas indicates purifying selection in the coding regions of orthologous genes and provides justification that genes identified as osmoregulatory in $C$. gigas are likely to maintain the same function in C. virginica. Even stronger justification is reported for a subset of osmoregulatory candidates that were expressed in only one of the two different salinity populations. Genes with an asymmetric expression pattern across the salinity gradient were significantly enriched for functions that may be related to osmoregulation, consistent with these genes having osmoregulatory functions in C. virginica.

Additionally, we have demonstrated that permissive clustering of contig and singleton sequences may improve downstream applications of assembled transcriptomes. In some de novo transcriptome assembly studies, the singleton reftigs are discarded and only the contigs are analyzed. Such a stringent filter, if applied here to $C$. virginica, would have eliminated 37,717 singletons that were successfully annotated. The goal of clustering is to keep the singletons and reduce redundancy across reftigs that can result from de novo assembly challenges due to factors such as sequencing error and high levels of polymorphism. Several studies 

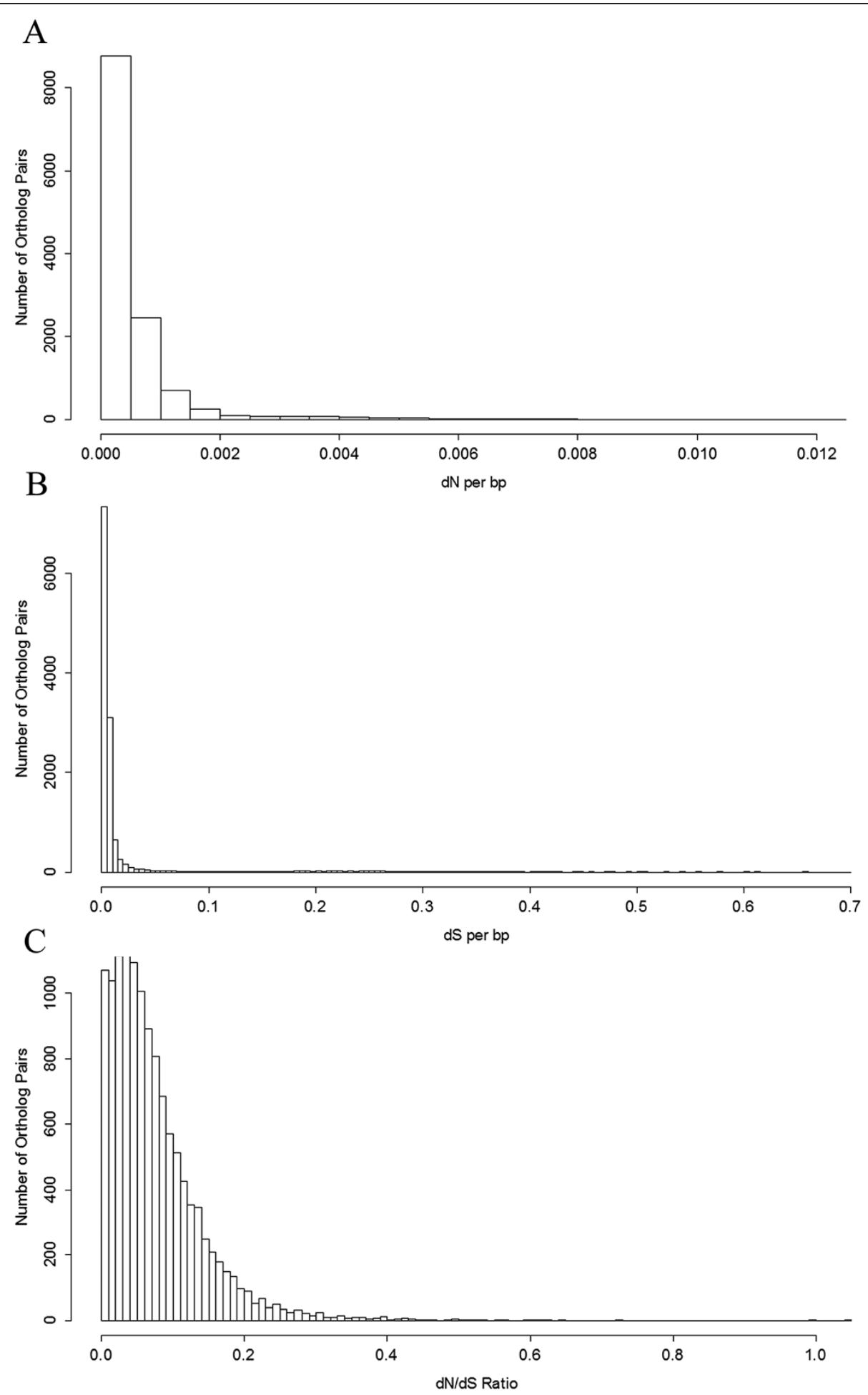

Figure 8 Distribution of (A) dN, (B) dS and (C) dN/dS ratio values. $d N$ and dS show similar distribution shapes with the number of synonymous substitutions much larger than the number of nonsynonymous substitutions. Most ortholog pairs had a dN/dS ratio below 0.2 indicating a strong role for purifying selection on oyster peptide sequences.

employing programs such as Cd-hit to cluster sequences based on similarity used a threshold of $95 \%$ similarity $[7,49]$. We explored a range of threshold values from
99\% down to the lower limit of the algorithm at $80 \%$. The improvement in uniquely mapped reads may be beneficial for downstream applications, depending on 
experimental goals. For RNA-seq experiments, a greater number of uniquely mapped reads means that a greater percentage of data can be retained for the estimation of expression. Future development of these clustering procedures should focus on evaluating trade-offs, particularly with respect to the incorporation of sequencing error at more permissive clustering thresholds.

Finally, we have provided a valuable set of resources for eastern oyster research. We have annotated 50,736 reftigs, doubling the 48,183 C. virginica transcriptome contig sequences provided by Zhang et al. [7]. After careful filtering of these reftigs, we identified 218,777 candidate SNPs for use in genetic mapping or for population analyses. The 1,007 candidate genes for osmoregulation identified here will provide a reference for future studies on the molecular basis of osmoregulation in C. virginica, phenotypically plastic responses to salinity stress, and patterns of selective differentiation across heterogeneous environments.

\section{Availability of supporting data}

The data sets supporting the results of this article are available in the National Center for Biotechnology Information Short Read Archive, accession numbers SRS502377 (http://www.ncbi.nlm.nih.gov/biosample/SRS50 2377) and SRS502378 (http://www.ncbi.nlm.nih.gov/biosample/SRS502378), and in FigShare (http://dx.doi.org/ 10.6084/m9.figshare.873865).

\section{Additional files}

Additional file 1: Table S1. Annotation of osmoregulatory candidate transcriptome reftigs from C. virginica. Each row is an osmoregulatory candidate reftig identified from the $\mathrm{C}$. virginica transcriptome. The identification as an osmoregulatory candidate is from the match between the GenBank nr description (column 3) of the annotated reftig to the description of an osmoregulatory candidate identified by Zhang et al. [17] in the C. gigas genome. Information provided in the table for each reftig are the reftig length, GenBank nr description, nr e-value, UniProt match, UniProt e-value, UniProt ID, KEGG ID, and nucleotide sequence.

Additional file 2: Table S2. Significantly enriched gene ontologies for cellular components in osmoregulatory candidate genes. Osmoregulatory candidate genes were compared to the complete set of annotated genes, ordered by functional category. The $p$-value is derived from a Fisher's exact test implemented in topGO from Bioconductor. Indentations represent the 'parent:'child' tiered relationship of GO terms with deeper indentations representing more specific terminology relative to the boldface level-three 'parent' terms shown as enriched in Figure 5. Table S3. Significantly enriched gene ontologies for molecular functions in osmoregulatory candidate genes. Osmoregulatory candidate genes were compared to the complete set of annotated genes, ordered by functional category. The $p$-value is derived from a Fisher's exact test implemented in topGO from Bioconductor. Indentations represent the 'parent':'child' tiered relationship of GO terms with deeper indentations representing more specific terminology relative to the boldface level-three 'parent' terms shown as enriched in Figure 6. Table S4. Significantly enriched gene ontologies for cellular components from the low salinity population. Significantly enriched gene ontologies in 1:0 asymmetric genes from the low salinity population are ordered by $p$-value. The $p$-value is derived from a Fisher's exact test implemented in topGO from Bioconductor. Table S5. Significantly enriched gene ontologies for cellular components from the high salinity population. Significantly enriched gene ontologies in 1:0 asymmetric genes from the high salinity population are ordered by $p$-value. The $p$-value is derived from a Fisher's exact test implemented in topGO from Bioconductor. Table S6. Significantly enriched gene ontologies for molecular function from the low salinity population. Significantly enriched gene ontologies in 1:0 asymmetric genes from the low salinity population are ordered by $p$-value. The $p$-value is derived from a Fisher's exact test implemented in topGO from Bioconductor. Table S7. Significantly enriched gene ontologies for molecular function from the high salinity population. Significantly enriched gene ontologies in 1:0 asymmetric genes from the high salinity population are ordered by $p$-value. The $p$-value is derived from a Fisher's exact test implemented in topGO from Bioconductor.

\section{Competing interests}

The authors declare that they have no competing interests.

\section{Authors' contributions}

Both authors conceived of and designed the study. LE collected field samples and water quality data, extracted RNA, performed the assembly, annotation and analysis of the transcriptome sequences, and drafted the manuscript. MH advised in the assembly, annotation and analysis of the transcriptome sequences, and was involved in the development of the manuscript. Both authors edited the manuscript and approve of the final paper.

\section{Acknowledgements}

We thank Dr. Qi Sun and colleagues at Life Sciences Core Laboratories Computational Biology Service Unit (CBSU) of Cornell University for bioinformatics consultation. We are indebted to Dr. Suzy Strickler for a custom pipeline for dN/dS calculation. Thanks to Dr. Ximing Guo for generously providing C. gigas genomic resources. We also thank Dr. Colleen Burge and members of the Hare Lab for comments on this manuscript. We also express gratitude to Sigma Xi Grant-in-Aid of Research and Cornell University for funding.

Received: 12 December 2013 Accepted: 3 June 2014

Published: 20 June 2014

\section{References}

1. Coen LD, Luckenbach MW, Breitburg DL: The role of oyster reefs as essential fish habitat: a review of current knowledge and some new perspectives. Am Fish Soc Symp 1999, 34:303-307.

2. Coen LD, Brumbaugh RD, Bushek D, Grizzle R, Luckenback MW, Posey MH, Powers SP, Tolley SG: Ecosystem services related to oyster restoration. Mar Ecol Prog Ser 2007, 341:303-307.

3. Zu Ermgassen PSE, Spalding MD, Grizzle RE, Brumbaugh RD: Quantifying the loss of a marine ecosystem service: Filtration by the eastern oyster in US estuaries. Estuar Coasts 2013, 36:36-43.

4. Beck MW, Brumbaugh RD, Airoldi L, Carranza A, Coen LD, Crawford C, Defeo O, Edgar GJ, Hancock B, Kay M, Lenihan HS, Luckenbach MW, Toropova CL, Zhang G, Guo X: Oyster reefs at risk and recommendations for conservation, restoration and management. Bioscience 2011, 61:107-116.

5. Willberg MJ, Livings ME, Barkman JS, Morris BT, Robinson JM: Overfishing, disease, habitat loss, and potential extirpation of oysters in the upper Chesapeake Bay. Mar Ecol Prog Ser 2011, 436:131-144.

6. Chapman RW, Mancia A, Beal M, Veloso A, Rathburn C, Blair A, Holland AF, Warr GW, Didinato G, Sokolova IM, Wirth EF, Duffy E, Sanger D: The transcriptomic response of eastern oyster, Crassostrea virginica, to environmental conditions. Mol Ecol 2011, 20(7):1431-1449.

7. Zhang L, Li L, Zhu Y, Zhang G, Guo X: Transcriptome analysis reveals a rich gene set related to innate immunity in the eastern oyster (Crassostrea virginica). Mar Biotechnol 2013, 2013:1-17.

8. Goedken M, Morsey B, Sunila I, de Guise S: Immunomodulation of Crassostrea gigas and Crassostrea virginica cellular defense mechanisms by Perkinsus marinus. J Shellfish Res 2005, 24(2):487-496. 
9. Tanguy A, Guo X, Ford SE: Discovery of genes expressed in response to Perkinsus marinus challenge in Eastern (Crassostrea virginica) and Pacific (Crassostrea gigas) oysters. Gene 2004, 338(1):121-131.

10. Jenny MJ, Ringwood AH, Lacy ER, Lewitus AJ, Kempton JW, Gross PS, Warr GW, Chapman RW: Potential indicators of stress response identified by expressed sequence tag analysis of hemocytes and embryos from the American oyster, Crassostrea virginica. Mar Biotechnol 2002, 4(1):81-93.

11. Anderson RS, Burreson EM, Paynter KT: Defense responses of hemocytes withdrawn from Crassostrea virginica infected with Perkinsus marinus. J Invertebr Pathol 1995, 66:82-89.

12. Ivanina AV, Taylor C, Sokolova IM: Effects of elevated temperature and cadmium exposure on stress protein response in eastern oysters Crassostrea virginica (Gmelin). Aquat Toxicol 2009, 91(3):245-254.

13. Loosanoff $\mathrm{VL}$ : Behavior of oysters in waters of low salinity. Proceed Natl Shellfisheries Assoc 1952, 1953:135-151.

14. Shaw WN: Oyster setting in two adjacent tributaries of Chesapeake Bay. ASB Bull 1966, 13(2):45.

15. Shumway SE: Natural environmental factors. In The Eastern Oyster Crassostrea virginica. Edited by Kennedy VS, Newell RIE, Eble AF. College Park, Maryland: Maryland Sea Grant College Publication; 1996:467-513.

16. Eierman LE, Hare MP: Survival of oyster larvae in different salinities depends on source population within an estuary. J Exp Mar Biol Ecol 2013, 449:61-68.

17. Zhang G, Fang X, Guo X, Li L, Luo R, Xu F, Yang P, Zhang L, Wang X, Qi H, Xiong Z, Que H, Xie Y, Holland PWH, Paps J, Zhu Y, Wu F, Chen Y, Wang J, Peng C, Meng J, Yang L, Liu J, Wen B, Zhang N, Huang Z, Zhu Q, Feng Y, Mount A, Hedgecock D, et al: The oyster genome reveals stress adaptation and complexity of shell formation. Nature 2012, 490:49-54.

18. Meng J, Zhu Q, Zhang L, Li C, Li L, She Z, Huang B, Zhang G: Genome and transcriptome analyses provide insight into the euryhaline adaptation mechanism of Crassostrea gigas. PLoS One 2013, 8(3):e58563. doi:10.1371/journal.pone.0058563.

19. Zhao Z, Yu H, Kong K, Li Q: Transcriptomic responses to salinity stress in the Pacific oyster Crassostrea gigas. PLoS One 2012, 7(9):e46244. doi:10.1371/journal.pone.0046244.

20. Evans DH: Osmotic and lonic Regulation: Cells and Animals. Boca Raton: CRC Press; 2009.

21. Pierce SK: Invertebrate cell volume control mechanisms: A coordinated use of intracellular amino acids and inorganic ions as osmotic solute. Biol Bull 1982, 163:405-419. http://dx.doi.org/10.2307/1541452.

22. Hosoi M, Kubota S, Toyohora M, Toyohora H, Hayashi I: Effect of salinity change on free amino acid content in Pacific oyster. Fish Sci 2003, 69(2):395-400

23. Pierce SK, Rowland-Faux LM, O'Brien SM: Different salinity tolerance mechanisms in Atlantic and Chesapeake Bay conspecific osyters: glycine betaine and amino acid pool variations. Mar Biol 1992, 113:107-115.

24. Yancey PH: Organic osmolytes as compatible, metabolic and counteracting cytoprotectants in high osmolarity and other stresses. J Exp Biol 2005, 208:2819-2830.

25. Toyohora H, Yoshida M, Hosoi M, Hayashi I: Expression of taurine transporter in response to hupo-osmotic stress in the mantle of Mediterranean blue mussel. Fish Sci 2005, 71:356-360.

26. Hosoi M, Shinzato C, Masaya T, Hosoi-Tanabe S, Sawada H, Terasawa E, Toyohara H: Taurine transporter function from the giant Pacific oyster Crassostrea gigas: function and expression in response to hyper- and hypo-osmotic stress. Fish Sci 2007, 73:385-394.

27. Ren J, Liu X, Jiang F, Guo X, Liu B: Unusual conservation of mitochondrial gene order in Crassostrea oysters: evidence for recent speciation in Asia. BMC Evol Biol 2010, 10:394

28. Lambert JD, Chan XY, Spiecker B, Sweet HC: Characterizing the embryonic transcriptome of the snail llyanassa. Integr Comp Biol 2010, 50(5):768-777.

29. Meyer E, Aglyamova GV, Wang S, Buchanan-Carter J, Abrego D, Colbourne $\mathrm{JK}$, Willis BL, Matz MV: Sequencing and de novo analysis of a coral larval transcriptome using 454 GSFIx. BMC Genomics 2009, 10:219.

30. Wolf JBW, Bayer T, Haubold B, Schilhabel M, Rosenstiel P, Tautz D: Nucleotide divergence vs. gene expression differentiation: comparative transcriptome sequencing in natural isolates from the carrion crow and its hybrid zone with the hooded crow. Mol Ecol 2010, 19:162-175.

31. Li W, Godzik A: Cd-hit: a fast program for clustering and comparing large sets of protein or nucleotide sequences. Bioinformatics 2006, 22(13):1658-1659.

32. Li H, Durbin R: Fast and accurate short read alignment with Burrows-Wheeler Transform. Bioinformatics 2009, 25:1754-1760.
33. Li H, Handsaker B, Wysoker A, Fennell T, Ruan J, Homer N, Marth G, Abecasis G, Durbin R: The Sequence Alignment/Map format and SAMtools. Bioinformatics 2009, 25(16):2078-2079.

34. Alexa A, Rahnenfuhrer J: topGO: Enrichment analysis for Gene Ontology. R Package Version 2010, 2:12.0.

35. Smit AFA, Hubley G, Green P: RepeatMasker Open-3.0. 1996-2010. http://www.repeatmasker.org.

36. Iseli $C$, Jongeneel CV, Bucher P: ESTScan: a program for detecting, evaluating, and reconstructing potential coding regions in EST sequences. Proc Int Conf Intell Syst Mol Biol 1999, 1999:138-148.

37. Larkin MA, Blackshields G, Brown NP, Chenna R, McGettigan PA, McWilliams $H$, Valentin F, Wallace IM, Wilm A, Lopez R, Thompson JD, Gibson TJ, Higgins DG: Clustal W and Clustal X version 2.0. Bioinformatics 2007, 23(21):2947-2948.

38. Yang Z: PAML 4:Phylogenetic Analysis by Maximum Likelihood. Mol Biol Evol 2007, 24(8):1586-1591.

39. Raineri E, Ferretti L, Esteve-Codina A, Nevado B, Heath S, Pérez-Enciso M: SNP calling by sequencing pooled sample. BMC Bioinform 2012, 13:239.

40. Philipp EER, Kraemer L, Melzner F, Poustka AJ, Thieme S, Findeisen U, Schreiber S, Rosenstiel P: Massively Parallel RNA Sequencing Identifies a Complex Immune Gene Repertoire in the lophotrochozoan Mytilus edulis. PLoS One 2012, 7(3):e33091. doi:10.1371/journal.pone.0033091.

41. Bettencourt R, Pinheiro M, Egas C, Gomes P, Afonso M, Shank T, Santos RS: High-throughput sequencing and analysis of the gill tissue transcriptome from the deep-sea hydrothermal vent mussel Bathymodiolus azoricus. BMC Genomics 2010, 11:559.

42. Bai Z, Zheng H, Lin J, Wang G, Li J: Comparative Analysis of the Transcriptome in Tissues Secreting Purple and White Nacre in the Pearl Mussel Hyriopsis cumingii. PLoS One 2013, 8(1):e53617. doi:10.1371/journal. pone.0053617.

43. Huan P, Wang H, Liu B: Transcriptomic analysis of the clam Meretrix meretrix on different larval stages. Mar Biotechnol 2012, 14:69-78.

44. Hou R, Bao Z, Wang S, Su H, Li Y, Du H, Hu J, Wang S, Hu X: Transcriptome Sequencing and De Novo Analysis for Yesso Scallop (Patinopecten yessoensis) Using 454 GS FLX. PLoS One 2011, 6(6):e21560. doi:10.1371/ journal.pone.0021560.

45. Milan M, Coppe A, Reinhardt R, Cancela LM, Leite RB, Saavedra C, Ciofi C, Chelazzi G, Patarnello T, Bortoluzzi S, Bargelloni L: Transcriptome sequencing and microarray development for the Manila clam, Ruditapes philippinarum: genomic tools for environmental monitoring. BMC Genomics 2011, 12:234.

46. Coppe A, Bortoluzzi S, Murari G, Marino IAM, Zane L, Papetti C: Sequencing and Characterization of Striped Venus Transcriptome Expand Resources for Clam Fishery Genetics. PLoS One 2012, 7(9):e44185. doi:10.1371/journal. pone.0044185.

47. Clark MS, Thorne MAS, Vieira FA, Cardoso JCR, Power DM, Peck LS: Insights into shell deposition in the Antarctic bivalve Laternula elliptica: gene discovery in the mantle transcriptome using 454 pyrosequencing. BMC Genomics 2010, 11:362

48. Qin J, Huang Z, Chen J, Zou Q, You W, Ke C: Sequencing and de novo Analysis of Crassostrea angulata (Fujian Oyster) from 8 Different Developing Phases Using 454 GSFIx. PLoS One 2012, 7(8):e43653. doi:10.1371/journal.pone.0043653.

49. Shi Y, Yu C, Gu Z, Zhan X, Wang Y, Wang A: Characterization of the Pearl Oyster (Pinctada martensii) mantle transcriptome unravels biomineralization genes. Mar Biotechnol 2013, 15:175-189.

50. Joubert C, Piquemal D, Marie B, Manchon L, Pierrat F, Zanella-Cléon I, Cochennec-Laureau N, Gueguen Y, Montagnani C: Transcriptome and proteome analysis of Pinctada margaritifera calcifying mantal and shell: focus on biomineralization. BMC Genomics 2010, 11:613.

51. Eierman LE, Hare MP: Crassostrea virginica transcriptome. FigShare 2013b. Available online at http://dx.doi.org/10.6084/m9.figshare.873865.

52. Cheung F, Haas BJ, Goldberg SMD, May GD, Xiao Y, Town CD: Sequencing Medicago truncatula expressed sequence tags using 454 Life Science technology. BMC Genomics 2006, 7:272.

53. Vera JC, Wheat CW, Fescemyer HW, Frilander MJ, Crawford DL, Hanski I, Marden JH: Rapid transcriptome characterization for a nonmodel organism using 454 pyrosequencing. Mol Ecol 2008, 17(7):1636-1647.

54. Calvo GW, Luckenback MW, Allen SK Jr, Burreson EM: Comparative field study of Crassostrea gigas and Crassostrea virginica in relation to salinity in Virginia. J Shellfish Res 1999, 18:465-473. 
55. Chu FE, La Peyre JF, Burreson CS: Perkinsus marinus infection and potential defense-related activities in eastern oysters, Crassostrea virginica: Salinity effects. J Invertebr Pathol 1993, 62(3):226-232.

56. Quilang J, Wang S, Li P, Abernathy J, Peatman E, Wang Y, Wang L, Shi Y, Wallace R, Guo X, Liu Z: Generation and analysis of ESTs from the eastern oyster, Crassostrea virginica Gmelin and identification of microsatellite and SNP markers. BMS Genomics 2007, 8:157.

57. Zhang L, Guo X: Development and validation of single nucleotide polymorphism markers in the eastern oyster Crassostrea virginica Gmelin by mining ESTs and resequencing. Aquaculture 2010, 302:124-129.

58. Yu H, He Y, Wang X, Zhang Q, Bao Z, Guo X: Polymorphism in a serine protease inhibitor gene and its association with disease resistance in the eastern oyster (Crassostrea virginica Gmelin). Fish Shellfish Immunol 2011, 30(3):757-762.

59. Vijay N, Poelstra JW, Künstner A, Wolf JBW: Challenges and strategies in transcriptome assembly and differential gene expression quantification. A comprehensive in silico assessment of RNA-seq experiments. Mol Ecol 2013, 22:620-634.

doi:10.1186/1471-2164-15-503

Cite this article as: Eierman and Hare: Transcriptomic analysis of candidate osmoregulatory genes in the eastern oyster Crassostrea virginica. BMC Genomics 2014 15:503.

\section{Submit your next manuscript to BioMed Central and take full advantage of:}

- Convenient online submission

- Thorough peer review

- No space constraints or color figure charges

- Immediate publication on acceptance

- Inclusion in PubMed, CAS, Scopus and Google Scholar

- Research which is freely available for redistribution 